\title{
Combining Near- and Farfield Exposure for an Organ- Specific and Whole-Body RF-EMF Proxy for Epidemiological Research: A Reference Case
}

\begin{tabular}{|r|l|}
\hline Journal: & Bioelectromagnetics \\
\hline Manuscript ID: & BEM-12-0003.R2 \\
\hline Wiley - Manuscript type: & Research Article \\
\hline Complete List of Authors: & $\begin{array}{r}\text { Lauer, Oliver; Laboratory for Electromagnetic Fields and Microwave } \\
\text { Electronics, Swiss Federal Institute of Technology Zurich } \\
\text { Frei, Patrizia; Swiss Tropical and Public Health Institute, Department of } \\
\text { Epidemiology and Public Health } \\
\text { Gosselin, Marie-Christine; IT'IS Foundation, } \\
\text { Joseph, Wout; Ghent University/IBBT, Information Technology } \\
\text { Röösli, Martin; Swiss Tropical and Public Health Institute, Department of } \\
\text { Epidemiology and Public Health } \\
\text { Fröhlich, Jürg; ETH Zürich, Laboratory for Electromagnetic Fields and } \\
\text { Microwave Electronics }\end{array}$ \\
\hline Keywords: & \begin{tabular}{l} 
Personal Exposure, SAR, Dose, Near-field, Far-field \\
\hline
\end{tabular} \\
\hline
\end{tabular}




\section{EIH}

Eidgenössische Technische Hochschule Zürich Swiss Federal Institute of Technology Zurich

\author{
Laboratory for Electromagnetic Fields and \\ Microwave Electronics \\ Swiss Federal Institute of Technology Zürich \\ Gloriastrasse 35 / ETZ K87 \\ $\mathrm{CH}-8092$ Zürich \\ Oliver Lauer \\ Tel. +49-17696714491 \\ olauero@gmail.com \\ www.ifh.ee.ethz.ch
}

\section{Combining Near- and Farfield Exposure for an Organ- Specific and Whole-Body RF-EMF Proxy for Epidemiological Research: A Reference Case}

Oliver Lauer ${ }^{1}$, Patrizia Frei ${ }^{2}$, Marie-Christine Gosselin ${ }^{3}$, Wout Joseph ${ }^{4}$, Martin Röösli ${ }^{2}$ and Jürg Fröhlich ${ }^{1, *}$

${ }^{1}$ Laboratory for Electromagnetic Fields and Microwave Electronics, Swiss Federal Institute of Technology, Zurich, Switzerland

${ }^{2}$ Institute of Social and Preventive Medicine at Swiss Tropical Institute Basel, Switzerland ${ }^{3}$ Foundation for Research on Information Technologies in Society (IT'IS), Zurich, Switzerland ${ }^{4}$ Ghent University / Institute for Broadband Technology (IBBT), Department of Information Technology, Ghent, Belgium

*Corresponding author e-mail: j.froehlich@ifh.ee.ethz.ch

\section{Running title: OSA and WBA Exposure Dose for NF and FF Exposure}

Grants: This work was supported by Eidgenössische Technische Hochschule (ETH) Research Grant (ETH-3108-2) and the Swiss National Foundation (Grant 405740-113595), which is part of the National Research Program 57 "Non-Ionising Radiation-Health and Environment". W. Joseph is a Post-Doctoral Fellow of the FWO-V (Research Foundation-Flanders). 


\begin{abstract}
A framework for the combination of near-field and far-field radio frequency electromagnetic exposure sources to the average organ and whole body specific absorption rates (SAR) is presented. As a reference case, values based on numerically derived SARs for whole body and individual organs and tissues are combined with realistic exposure data, which have been collected during the Swiss Qualifex study using personal exposure meters. The framework presented can be applied to any study region where exposure data is collected by appropriate measurement equipment.

Based on the results derived for the data in the region of Basel in Switzerland the relative importance of near-field and far-field sources to the personal exposure is examined for three different study groups. The results show that the 24 hour whole-body averaged exposure of an average mobile phone user is dominated by the use of his or her own mobile phone when a global system for mobile communication (GSM) 900 or GSM 1800 phone is used. If only universal mobile telecommunications system (UMTS) phones are used the user would experience a lower exposure level on average caused by lower average output power of the UMTS phones. Data presented clearly indicates the necessity of collecting band selective exposure data in epidemiological studies related to electromagnetic fields.

The data for the whole body and organ specific SARs derived from the numerical model presented in this paper can be used to derive the exposure of multiple sources in an everyday environment for use in epidemiological studies on possible specific and non-specific health effects caused by radio frequency electromagnetic fields when combined with the corresponding band selective exposure data.
\end{abstract}

\title{
Key Words: Personal Exposure, SAR, Dose, Near-field, Far-field
}




\section{Introduction}

Technologies using electromagnetic (EM) fields are more and more employed in our society. Therefore, people are exposed to various sources in their vicinity such as mobile phones, cordless phones and base stations. In general, the contribution to the personal exposure can be divided into near-field (NF) and far-field (FF) sources with respect to the human body. NF sources, such as cell phones, are operating in the close vicinity of the body and are usually controlled by the user. They can cause temporarily high local exposure, whereas FF sources, such as radio base stations, are usually further away and thus lead to lower but rather continuous exposure levels. For a thorough study of potential specific and non-specific health effects, caused by radio frequency $(\mathrm{RF})$ electromagnetic fields (EMF), the contribution of different radio frequency sources to the personal exposure of different organs, body tissues and for the whole body is required.

In the past different exposure proxies were used in order to classify different exposure groups. In Neubauer et al. [2007] the feasibility of epidemiological studies on possible health effects of mobile phone base stations is evaluated. An extensive discussion on previous approaches can be found together with a collection of references. In conclusion epidemiological studies are considered as feasible if the contribution of the different sources to the RF exposure can be assessed by appropriate means such as personal exposure meters. However, the combination of FF and NF sources by weighting with exposure data collected in the corresponding study area was not discussed so far.

In this paper a reference case for combining the contributions of NF and FF radio frequency electromagnetic exposure sources to the average organ and whole body specific exposure is investigated. Therefore, a detailed collection of numerically derived specific absorption rates (SAR) of whole-body averaged (WBA) and organ-specific averaged (OSA) for NF and FF 
exposure scenarios are required. The corresponding SAR values are derived from numerical simulations using anatomical human body models as presented in Christ et al. [2010a]. Although a few studies have been performed to calculate WBA and OSA SAR values for different scenarios as in Kuehn et al. [2009], Dimbylow et al. [2008], Catarinucci et al. [2003] and Meyer et al. [2003] these results aimed to test compliance with given exposure limits from regulatory bodies and do not provide results of all sources which we are exposed to in everyday life. In order to close this gap, the WBA SAR and the OSA SAR are calculated using the Virtual Family Model (VFM) 'Duke' that is considered as representative of average male humans in the population [Gosselin et al., 2011] and the SAR values are provided for both NF and FF exposure sources at the required carrier frequencies of the RF services. The NF exposure scenario is represented by a cell phone, operating at the right head side of the human model, whereas the FF exposure scenario is characterized by the irradiation of the human model by plane waves. The normalized results from the numerical calculations are combined and weighted with the corresponding exposure values collected in the Qualifex study [Frei et al., 2009] to calculate the personal dose values in terms of time averaged SAR. The results show the relative importance of $\mathrm{NF}$ and FF sources to the personal exposure in the specific study area and can be used as exposure proxies in epidemiological studies on potential specific and non-specific health effects caused by RF sources.

\section{Material and methods}

\section{Simulated exposure scenarios}

For the simulations the commercially available simulation platform SEMCAD X (Version 14, Schmid \& Partner Engineering AG, Zurich, Switzerland) and the 'Duke'-model [Christ et al., 2010a] of 'The Virtual Family' were used. The 'Duke'-model is generated from a set of 
magnetic resonance images of whole body scans from a 34 year old male. The male is $1.74 \mathrm{~m}$ tall, weighs $72 \mathrm{~kg}$ and has a body mass index of $23.1 \mathrm{~kg} / \mathrm{m}^{2}$. The dielectric tissue properties have been assigned according to the integrated material database in SEMCAD $X$ that is based on previous databases updated according to additional published literature values. The database is documented on the download site [Database of tissue properties, 2012]. The values given in the database correspond to average values. Standard deviations of the tissue properties together with literature references are also reported in the documentation provided on the webpage. The resolution of the model was chosen to be $2 \times 2 \times 2 \mathrm{~mm}$ resulting in a total of about 110 million voxels. The computational domain is terminated by uniaxial anisotropic perfectly matched layer (UPML) boundary conditions.

\section{Far-field}

As FF sources the following radio frequency $(\mathrm{RF})$ services are considered: frequency modulation (FM) radio stations, television (TV) broadcast stations, wireless fidelity (WiFi) hotspots and mobile phone base stations, including global system for mobile communication (GSM) 900, GSM 1800, universal mobile telecommunications system (UMTS) and digital enhanced cordless telecommunications (DECT). Therefore, simulations at the following frequencies were performed: $100 \mathrm{MHz}$ (FM), $650 \mathrm{MHz}$ (TV), 900 MHz (GSM 900), 1800 MHz (GSM 1800), $1950 \mathrm{MHz}$ (UMTS, DECT) and $2450 \mathrm{MHz}$ (WiFi). As a FF exposure scenario the human model is irradiated by 12 identical plane waves coming from the six major incident directions with two polarizations each is selected. The WBA SAR $\mathrm{FF}$ and the OSA SAR $\mathrm{FF}$ is calculated for each configuration separately and the results are averaged over all incident directions resulting in a 
maximum average value for the number of plane waves considered. The simulation results are normalized to a power flux density of $1 \mathrm{~W} / \mathrm{m}^{2}$.

\section{Near-field}

The main contribution to the exposure from NF sources is caused by the cell phones and the cordless phones. These phones use either the GSM 900, GSM 1800, UMTS or DECT standard. This exposure scenario is modeled by a cell phone, operating at the right side of the human model's head. As a phone model the (T250, Motorola, Schaumburg, IL, USA) is selected. Simulations are performed at the operating frequencies of the services at $900 \mathrm{MHz}, 1750 \mathrm{MHz}$ and $1950 \mathrm{MHz}$. For both UMTS and DECT the simulation results from $1950 \mathrm{MHz}$ are used, due to the low frequency separation of the UMTS uplink and the DECT band. The numerical computation was carried out according the procedure described in Christ et al. [2010b]. The WBA SAR and the OSA SAR are calculated for each carrier frequency separately and the results are normalized to an output power of the phone of 1 Watt.

\section{Realistic exposure data}

The simulated results of the WBA and OSA SAR are used to analyze the relative importance of NF and FF sources to the personal whole body or organ and tissue specific dose. Furthermore, the following calculations serve as an example how the simulation-derived data can be applied to exposure data collected with exposimeters in epidemiological studies. Figure 1 shows a flow graph of the applied method to calculate realistic FF and NF exposure doses. The required parameters for these calculations as well as their sources are listed. Within this scope, we used data from a Swiss personal RF EMF exposure survey (Qualifex study) [Frei et al., 2009]. In the 
Swiss survey 166 study participants carried a personal exposimeter (EME SPY120, Satimo, Courtaboeuf, France) in the region of Basel over a period of one week.

According to [Frei et al., 2009] three different exposure groups are defined: Group I: persons with residency close to a broadcast transmitter, Group II: self-selected volunteers, Group III: persons with residency close to a mobile phone base station.

Table 1 shows the average incident measured fields for the three exposure groups in terms of the power flux density $S$. The values represent FF exposure values, since measurements that have been taken during the use of mobile and cordless phones were excluded from the calculation of mean values [Frei et al., 2009]. The personal FF dose averaged over 24 hours of a group is determined as a sum over the contributions of all services. The contribution of a service $i$ is computed as the normalized WBA $\mathrm{SAR}_{\mathrm{FF}}$ induced by the specific service weighted by the corresponding power flux density $S$. The dose of a group can be written as:

$$
\text { WBADose }_{F F}(\text { Group }, 24 h)=24 \times 3600 \mathrm{~s}\left(\sum_{i} W_{B} A S A R_{F F}\left(\text { service }_{i}\right) \times S_{\text {service }_{i}}\right) \text { Equation } 1
$$

Regarding exposure close to body sources we used data from the Qualifex main study, i.e., 1375 study participants that were randomly selected from the urban and suburban area of Basel, Switzerland. The results show that the volunteers used their cell phone on average 25.6 min/week and their DECT phone $61.6 \mathrm{~min} /$ week, see [Mohler et al., 2009].

In addition to the usage data, we used data of the average output power measured at the antenna feed point of typical cell phones provided by literature. Table 2 summarizes the average transmission (TX) powers of the different services and the average call times. The values for GSM 900 and GSM 1800 are taken from Vrijheid et al. [2009], where the average output power of GSM 900 and GSM 1800 cell phones was evaluated with software modified phones considering more than 500 volunteers in 12 countries. The average transmission power of UMTS 
phones was evaluated in Gati et al. [2009]. In our analysis we are assuming that 50\% of the phone calls are made in buildings and $50 \%$ outdoor (in a large city). This leads to an average output power of $0.65 \mathrm{~mW}$. In general, a DECT phone uses one of 24 time slots with a constant transmission power of $250 \mathrm{~mW}$. This leads to an average output power of $250 \mathrm{~mW} / 24=10.4$ $\mathrm{mW}$.

The resulting personal NF dose is determined by the normalized WBA $\mathrm{SAR}_{\mathrm{NF}}$ and the normalized OSA SAR $\mathrm{NF}_{\mathrm{N}}$ weighted by the average output power $\mathrm{P}_{\mathrm{i}}$ of the phone and the average call time $\mathrm{T}_{\mathrm{i}}$ of the specific used mobile service $\mathrm{i}$. The results are calculated for a 24-hour exposure:

WBADose $_{N F}\left(\right.$ service $\left._{i}, 24 h\right)=24 \times 3600 \mathrm{~s}\left(\sum_{i}\right.$ WBASAR $_{N F}\left(\right.$ service $\left.\left._{i}\right) \times P_{i} \times \frac{T_{i}}{T}\right)$ Equation 2 where $T$ is the reference time of $T_{i}$. When $T_{i}$ is given in min per week then $T$ would be $7 \times 24 \times 60$ min. The "OSA Dose ( service $_{i}, 24 \mathrm{~h}$ )" can be obtained from the OSA SAR in a similar way.

\section{Results}

Simulation results

Whole-body averaged specific absorption rate Far-field

Figure 2 shows the WBA SAR ${ }_{\mathrm{FF}}$ calculated at $100 \mathrm{MHz}, 650 \mathrm{MHz}, 900 \mathrm{MHz}, 1800 \mathrm{MHz}, 1950$

$\mathrm{MHz}$ and $2450 \mathrm{MHz}$. The simulation results are normalized to a power flux density of $1 \mathrm{~W} / \mathrm{m}^{2}$.

The results show a higher absorption for lower frequencies which can be explained by resonance effects and a larger penetration depth for lower frequencies. 


\author{
Near-field \\ The normalized WBA SAR $\mathrm{NF}_{\mathrm{N}}$ is calculated for the human model with a cell phone that is placed \\ to the right side of the head for $900 \mathrm{MHz}, 1800 \mathrm{MHz}$ and $1950 \mathrm{MHz}$. The results are given in \\ Table 3 and they are normalized to an output power of the phone of 1 Watt. The results show a \\ higher WBA SAR for higher frequencies.
}

\title{
Organ-specific averaged absorption rate
}

With regard to potential health effects caused by RF EMF exposure, organs and tissues that directly or indirectly influence hormonal balance or cell growth are of greater interest, because they can serve as an indicator of possible influences of electromagnetic exposure. Therefore, we will focus only on the OSA SAR for the most important organs and tissues. In this context we chose 24 different organs and tissues as listed in Table 4.

The simulation setup for the calculation of the OSA SAR is the same as for the WBA SAR calculation, see section Simulated exposure scenarios.

\section{Far-field}

Table 4 shows the OSA SAR ${ }_{\mathrm{FF}}$ for $100 \mathrm{MHz}, 650 \mathrm{MHz}, 900 \mathrm{MHz}, 1800 \mathrm{MHz}, 1950 \mathrm{MHz}$ and $2450 \mathrm{MHz}$. The data are normalized to a power flux density of $1 \mathrm{~W} / \mathrm{m}^{2}$. The results are highly

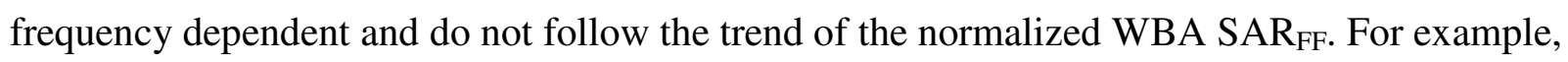
the heart muscle has a maximum absorption at $100 \mathrm{MHz}$ and a minimum at $2450 \mathrm{MHz}$, whereas the skin has a maximum at $2450 \mathrm{MHz}$ and a minimum at $100 \mathrm{MHz}$. The reason for that is the higher penetration depth for lower frequencies. 
Near-field

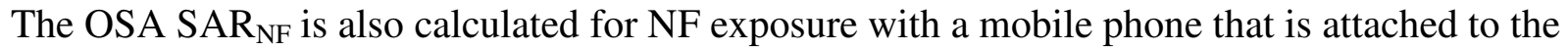
head of the human body model. Table 5 summarizes the OSA SAR $\mathrm{NF}_{\text {for }} 900 \mathrm{MHz}, 1800 \mathrm{MHz}$ and $1950 \mathrm{MHz}$. The data are normalized to an output power of the phone of $1 \mathrm{~W}$. The results show the highest absorption for the skin and head organs.

\section{Example with real exposure data}

In a next step the WBA SAR and OSA SAR results of the NF and FF simulations with the Virtual Family Model 'Duke' are weighted with personal exposure data collected within the Qualifex study. The results are evaluated for the three different FF exposure groups and for NF exposure.

The calculations follow the method shown in Figure 1.

\section{WBA dose}

Far-field

Figure 3 summarizes the results for the three examined study groups. It can be seen that people of Group I feature a higher "WBA Dose $\mathrm{FF}(24 \mathrm{~h})$ " than people of Group II and Group III. This can be explained by higher measured mean values [Frei et al., 2009] and a higher mean contribution of TV and radio stations to the FF exposure and the higher energy absorption at lower frequencies. The lowest "WBA Dose $\mathrm{FF}(24 \mathrm{~h})$ " is $35.2 \mathrm{~mJ} / \mathrm{kg}$ for people of the study Group II.

Near-field

Table 6 summarizes the "WBA Dose $\mathrm{NF}_{2}(24 \mathrm{~h})$ " for the three different mobile phone standards and for DECT. The transmission power for GSM 900, GSM 1800, UMTS and DECT and the call times are provided in Table 2. 
Far-field vs. Near-field

Figure 4 shows the difference between the NF and FF WBA dose in logarithmic scale for an average mobile phone user of Group II (self-selected volunteers). The NF exposure was either caused by a GSM 900, GSM 1800, UMTS or DECT phone. The results show that the WBA SAR for $\mathrm{NF}$ is $5 \mathrm{~dB}$ higher than for $\mathrm{FF}$ exposure, when the GSM 900 mobile service is used exclusively. Using the GSM 1800 service leads to a difference of $2.9 \mathrm{~dB}$, for UMTS to $-16.9 \mathrm{~dB}$ and for DECT to $1.1 \mathrm{~dB}$. In order to encounter the same WBA SAR for NF and FF sources the call time has to be decreased from $25.6 \mathrm{~min} /$ week to $8.1 \mathrm{~min} /$ week when using the GSM 900 standard, $13.1 \mathrm{~min} /$ week for GSM 1800 and $19.8 \mathrm{~min} /$ week for the DECT standard. In contrast, if only the UMTS standard is used, the call time could be increased to 20.9 hours/week. The overall personal dose "WBA Dose ${ }_{\text {all }}(24 \mathrm{~h})$ " consists of contributions from NF and FF sources. It can be calculated by the sum of the dose for NF (Equation 2) and FF (Equation 1) sources.

Assuming a person of Group II, who uses the mobile phone for $25.6 \mathrm{~min} /$ week in GSM 900 and the DECT phone for $61.6 \mathrm{~min} / \mathrm{week}$, the "WBA Dose all $(24 \mathrm{~h})$ " can be calculated to:

$$
\begin{aligned}
& \text { WBADose }_{\text {all }}(24 \mathrm{~h})=\text { WBADose }_{F F}(\mathrm{II}, 24 \mathrm{~h})+\text { WBADose }_{N F}(\mathrm{GSM} 900,24 \mathrm{~h})+ \\
& \text { WBADose }_{N F}(\mathrm{DECT}, 24 \mathrm{~h})=35.2 \mathrm{~mJ} / \mathrm{kg}+111 \mathrm{~mJ} / \mathrm{kg}+27.2 \mathrm{~mJ} / \mathrm{kg}=173.4 \mathrm{~mJ} / \mathrm{kg}
\end{aligned}
$$

The contribution of the different services to the "WBA Dose ${ }_{\text {all }}(24 \mathrm{~h})$ " is shown in Figure 5. The self-induced NF-exposure dose is indicated in the legends with the abbreviation 'self'. The results highlight that $80 \%$ of the dose is caused by the person's own mobile phone (GSM900self $=64 \%$, DECTself $=16 \%$ ) rather than by non-controlled sources in the surrounding environment. For a GSM1800 user the cell phone features a contribution of $52 \%$ and the DECT phone of $20 \%$, whereas for a UMTS user the cell phone has a contribution of $1 \%$ and the DECT phone of $43 \%$ to the total exposure. 


\title{
OSA dose
}

\section{Far-field}

The "OSA Dose $\mathrm{FF}(24 \mathrm{~h})$ ", which is caused by various FF sources, can be calculated by the

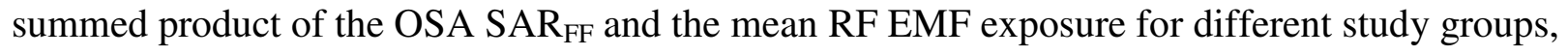
according to Equation 1. The first three columns in Table 7 summarize the "OSA Dose ${ }_{\mathrm{FF}}(24 \mathrm{~h})$ " for the three different study groups.

\begin{abstract}
Near-field
In order to compare OSA dose values, caused by NF and FF sources for an average user, the "OSA $\operatorname{SAR}_{\mathrm{NF}}(24 \mathrm{~h})$ " is calculated according to Equation 2. The used transmission power levels and the call times are given in Table 2. The columns "OSA Dose $\mathrm{NF}_{2}(24 \mathrm{~h})$ " in Table 7 shows the OSA dose values for an average mobile phone user, using either a GSM 900, GSM 1800 or UMTS phone. Furthermore, the OSA dose for an average DECT user is also listed. The results show that UMTS standard leads to the smallest OSA dose values, whereas GSM 900 caused the highest organ specific dose values due to the higher transmission power level of this standard.
\end{abstract}

\author{
Far-field vs. Near-field \\ Using the results of Table 7, the "OSA Dose $\mathrm{FF}_{\mathrm{F}}(24 \mathrm{~h})$ " can be compared with "OSA Dose $\mathrm{NF}^{\text {". The }}$ \\ results show that the UMTS user encounters in average smaller exposure levels by NF than by \\ FF sources for all analyzed organs. The reason for this is the lower average output power of a \\ UMTS phone. Figure 6 compares the induced exposure for five different organs (brain grey \\ matter, brain white matter, heart muscle, spinal cord and testis), caused by NF and FF sources. \\ The results show that the NF sources dominate the total exposure for the head for GSM 900, \\ GSM 1800 and DECT. Only UMTS induces smaller OSA dose values than the FF sources. In \\ order to encounter the same OSA dose for FF sources (Group II) and NF sources (UMTS phone)
}


for the brain (grey matter) the call time can be increased by a factor of 8.1 leading to a call time of $207 \mathrm{~min} /$ week.

\section{Discussion}

In this paper a set of numerically derived specific absorption rates of whole body and individual organs are presented for NF and FF exposure sources. This allows calculating the absorbed dose inside the body for given exposure data from multiple sources assessed by studies using exposimeters. The results can be used to support deriving exposure proxies for epidemiological studies of e.g., non-specific health effects caused by RF EMF. The use of the data is demonstrated for exposure data collected during the Qualifex study. Based on these results the relative importance of NF and FF sources to the total personal exposure dose is examined.

The results show that the "WBA Dose(24h)" of an average mobile phone user (25.6 min/week) is dominated by the use of his or her own mobile phone when a GSM 900 or GSM 1800 phone is used. The UMTS user encounters on average smaller exposure levels by NF than by FF sources for whole body and all analyzed organs. This is also true for organs close to the phone, i.e., brain. The reason for this is the lower average output power of a UMTS phone. For example, an average person that uses the UMTS standard exclusively, can increase his call time by a factor of 8.1 leading to total call time of $207 \mathrm{~min} /$ week in order to encounter the same dose caused by FF sources inside the grey matter of the brain.

The simulation results in the database refer each to a selected reference scenario, which are obviously subject to variations. For FF exposure, a scenario that represents an equal irradiation from the six main directions (2 polarizations each) was chosen. Analysis in the scope of variations for different irradiation scenarios showed in Vermeeren et al. [2009] that the wholebody averaged SAR for a realistic exposure exceeds the maximum average case of single plane 
wave exposure in approximately $10 \%$ of the exposure samples. A further variation is generally implied by the used human model in the simulations, see Kuehn et al. [2009]. Due to the highly diverse human population the simulation results of a single model cannot be generalized. In Conil et al. [2008] six numerical human models have been compared, and their variability in terms of morphology and behavior toward RF exposure for frequencies from $20 \mathrm{MHz}$ to $2.4 \mathrm{GHz}$ were analyzed. The results show that the standard deviation of the WBA SAR of adult models can reach up to $40 \%$.

The NF exposure scenario is represented by a phone model that is placed on the right head side of the virtual family male. Different factors such as the position of the phone model, type of the phone and the use of personal hand-free kits are affecting body exposure. When looking at the measured SAR values (averaged over $10 \mathrm{~g}$ of tissue) of different mobile phone types in a homogeneous head, a factor higher than 13 between different devices can be observed in worst case, see SAR database [2011]. This fact leads to a variation of OSA and WBA SAR for different phones, which has to be examined separately and is out of the scope of this paper. Therefore, further analysis are required in order to evaluate the variations of the WBA and OSA SAR such as phone type, phone position, human model and exposure scenario. However, the case presented here can be taken as a reference case where average scenarios were chosen together with available data from the literature on average power levels. Further work should focus on designing exposure assessment studies involving equipment able to record as much data as possible, in particular transmission power, position and operation mode of the mobile phone. Here, it has been shown that all the parameters involved in a "dose" definition based on time averaged power deposition in tissues, organs or the whole-body have a significant influence on the relation between the different contributions arising from different NF and FF RF sources. 
Therefore, in future epidemiological studies careful exposure assessment has to be carried out using appropriate equipment delivering the necessary data. Further, as long as no reproducible effect is detected and no explicit site of interaction is identified also different dose measures such as the power spectrum or band-selective data should be considered including as much information as possible for the case of retrospective analysis. For these cases the same framework presented here can be applied.

\section{References}

Catarinucci L, Palazzari P, Tarricone L. 2003. Human exposure to the near field radiobase antennas- a full wave solution using parallel FDTD. IEEE Trans. Microw. Theory Tech. 51(3):935-940.

Christ A, Kainz W, Hahn E, Honegger K, Zefferer M, Neufeld E, Rascher W, Janka R, Bautz W, Chen J, Kiefer B, Schmitt P, Hollenbach H, Shen J, Oberle M, Szczerba D, Kam A, Guag J, Kuster N. 2010a. The virtual family-development of surface-based anatomical models of two adults and two children for dosimetric simulations. Physics in Medicine and Biology 55:23-38.

Christ A, Gosselin MC, Christopoulou M, Kuehn S., Kuster N. 2010b. Age-dependent tissuespecific exposure of cell phone users. Physics in Medicine and Biology 55:1767-1783.

\footnotetext{
Conil E, Hadjem A, Lacroux F, Wong M, Wiart J. 2008. Variability analysis of SAR from 20 $\mathrm{MHz}$ to $2.4 \mathrm{GHz}$ for different adult and child models using finite-difference time-domain. Physics in Medicine and Biology 53(6): 1511-1525 .
} 
Database of tissue properties, [Online]. Available: http://www.itis.ethz.ch/database. Last accessed: 26. September 201

Dimbylow J, Hirata A, Nagaoka T. 2008. Intercomparison of whole-body averaged sar in european and japanese voxel phantoms. Physics in Medicine and Biology 53:5883-5897.

Frei P, Mohler E, Neubauer G, Theis G, Bürgi A, Fröhlich J, Braun-Fahrländer C, Bolte J, Egger M, and Röösli M. 2009. Temporal and spatial variability of personal exposure to radio frequency electromagnetic fields. Environ Res 109: 779-785.

Gati A, Hadjem A, Wong M-F, Wiart J. 2009. Measured output power distribution for 3g WCDMA mobile phones. IEEE Transactions on Wireless Communications 8(12): 5723-5725.

Gosselin M.-C., Vermeeren G., Kühn S., Kellerman V., Benkler S., Usitupa T. M. I., Joseph W., Gati A., Wiart J.,Meyer F. J. C., Martens L., Nojima T., Hikage T., Balzano Q., Christ A., Kuster N. 2011. Estimation Formulas for the Specific Absorption Rate in Humans Exposed to BaseStation Antennas, IEEE Trans. on Electromagnetic Compatibility 53(4).

\footnotetext{
Kuehn S, Jennings W, Christ A, Kuster N. 2009. Assessment of induced radio-frequency electromagnetic fields in various anatomical human body models. Physics in Medicine and Biology 54: 875-890.
} 
Meyer F, Davidson D, Jakobus U, Stuchly M. 2003. Human exposure assessment in the near field of GSM base-station antennas using a hybrid finite element method of moments technique. IEEE Trans. Biomed. Eng.50(2): 224-233.

\begin{abstract}
Mohler E, Frei P, Aydin A, Buergi A, Röösli M. 2009. Personal exposure to high-frequency electromagnetic fields in the region of Basel (Switzerland): An overview of the Qualifex-study. Umweltmed Forsch Prax 14(6):329-338.
\end{abstract}
Neubauer G., Feychting M., Hamnerius Y., Kheifets L., Kuster N., Ruiz I., Schütz J., Ueberbacher R., Wiart J., Röösli M., 2007. Feasibility of Future Epidemiological Studies on Possible Health Effects of Mobile Phone Base Stations, Bioelectromagnetics 28(3):224-230.

SAR database, [Online]. Available: http://www.sardatabase.com/. Last accessed: 3. January 2011

Vermeeren G, Joseph W, Christof O, Martens L. 2009. Statistical multipath exposure of a human in a realistic electromagnetic environment, Health Physics 94:345-354.

\author{
Vrijheid M, Mann S, Vecchia P, Wiart J, Taki M, Ardoino L, Armstrong BK, Auvinen A, \\ Bedard D, Berg-Beckhoff G, Brown J, Chetrit A, Collatz-Christensen H, Combalot E, Cook A, \\ Deltour I, Feychting M, Giles GG, Hepworth SJ, Hours M, Iavarone I, Johansen C, Krewski D, \\ Kurttio P, Lagorio S, Lonn S, McBride M, Montestrucq L, Parslow RC, Sadetzki S, Schuz J, \\ Tynes T, Woodward A, Cardis E. 2009. Determinants of mobile phone output power in a
}


multinational study: implications for exposure assessment. Occupational and Environmental Medicine 66:664-671.

1

2

5

6

7

8

9

10

11

12

13

14

15

16

17

18

19

20

21

22

23

24

25

26

27

28

29

30

31

32

33

34

35

36

37

38

39

40

41

42

43

44

45

46

47

48

49

50

51

52

53

54

55

56

57

58

59

60 
Figure 1: Picture of the flow graph for the dose calculations. The graph shows the required parameter for the calculations and also the sources of the parameters that were used.

Figure 2: Whole-body averaged (WBA) specific absorption rate $(\mathrm{SAR})_{\mathrm{FF}}$ for plane waves coming from the six major incident directions with two polarizations each at $100 \mathrm{MHz}, 650$ $\mathrm{MHz}, 900 \mathrm{MHz}, 1800 \mathrm{MHz}, 1950 \mathrm{MHz}$ and $2450 \mathrm{MHz}$. The results are averaged over all incident directions and normalized to a power flux density of $1 \mathrm{~W} / \mathrm{m}^{2}$.

Figure 3: Contribution of different far field (FF) services to the "WBA Dose $\mathrm{FF}_{\mathrm{FF}}(24 \mathrm{~h})$ " for different study groups. Group I: persons with residency close to a broadcast transmitter, Group II: self-selected volunteers, Group III: persons with residency close to a mobile phone base station.

Figure 4: "WBA Dose ratio(24h)" caused by near field (NF) and far field (FF) sources for an average mobile phone user of Group II.

Figure 5: Contribution of the different services to the total "WBA Dose all $(24 \mathrm{~h})$ " for a person from the study Group II. We assume that the person uses the GSM 900 service for 25.6 $\mathrm{min} /$ week and the DECT service for $61.6 \mathrm{~min} / \mathrm{week}$. The contribution of the self-induced exposure dose is indicated in the legends with the abbreviation 'self'.

Figure 6: Comparison of OSA dose for the study group II and the usage of different mobile and cordless phone standards. The average call time is $25.6 \mathrm{~min} /$ week for GSM 900, GSM 1800 and UMTS. For DECT an average call time of $61.6 \mathrm{~min} /$ week is assumed.

Table 1: Average incident fields from far field (FF) sources of three different exposure groups measured during the Qualifex study. The fields are given as electromagnetic field values $\mathrm{E}$ and the corresponding power flux density S.

Table 2: Average transmission power of a cell phone and a cordless phone. The average call time for the different evaluated scenarios is also given.

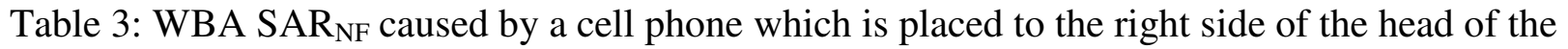
human model. The results are normalized to an output power of the phone of $1 \mathrm{~W}$.

Table 4: OSA SAR $\mathrm{FF}$ for plane wave exposure coming from the six major incident directions with two polarizations each at $100 \mathrm{MHz}, 650 \mathrm{MHz}, 900 \mathrm{MHz}, 1800 \mathrm{MHz}, 1950 \mathrm{MHz}$ and 2450 $\mathrm{MHz}$. The results are averaged over all incident directions and are normalized to a power flux density of $1 \mathrm{~W} / \mathrm{m}^{2}$. The labels of the organs are taken from the 'Duke'-model, see Christ et al. [2010a].

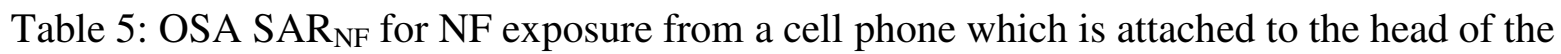
human model at $900 \mathrm{MHz}, 1800 \mathrm{MHz}$ and $1950 \mathrm{MHz}$. The results are normalized to an output 
power of the phone of $1 \mathrm{~W}$. The labels of the organs are taken from the 'Duke'-model, see Christ et al. [2010a].

Table 6: "WBA Dose $\mathrm{NF}_{\mathrm{N}}(24 \mathrm{~h})$ " caused by a phone which is attached to the head of the human model for different mobile phone standards. The average call time is $25.6 \mathrm{~min} / \mathrm{week}$ for GSM 900, GSM 1800 and UMTS. For DECT an average call time of $61.6 \mathrm{~min} /$ week is assumed.

Table 7: Table of OSA dose(24h) caused by FF sources for different study groups, exposed to various FF sources, and the NF-dose(24h) caused by a mobile phone which is attached to the head for different mobile phone standards. (Group I: persons with residency close to a broadcast transmitter, Group II: self-selected volunteers, Group III: : persons with residency close to a mobile phone base station). A call time $T_{i}$ of $25.6 \mathrm{~min} /$ week for GSM 900, GSM 1800, UMTS and $61.6 \mathrm{~min} /$ week for DECT is assumed. The labels of the organs are taken from the 'Duke'model, see Christ et al. [2010]. 
Figure 1: Picture of the flow graph for the dose calculations. The graph shows the required parameter for the calculations and also the sources of the parameters that were used. $135 \times 103 \mathrm{~mm}(300 \times 300 \mathrm{DPI})$ 


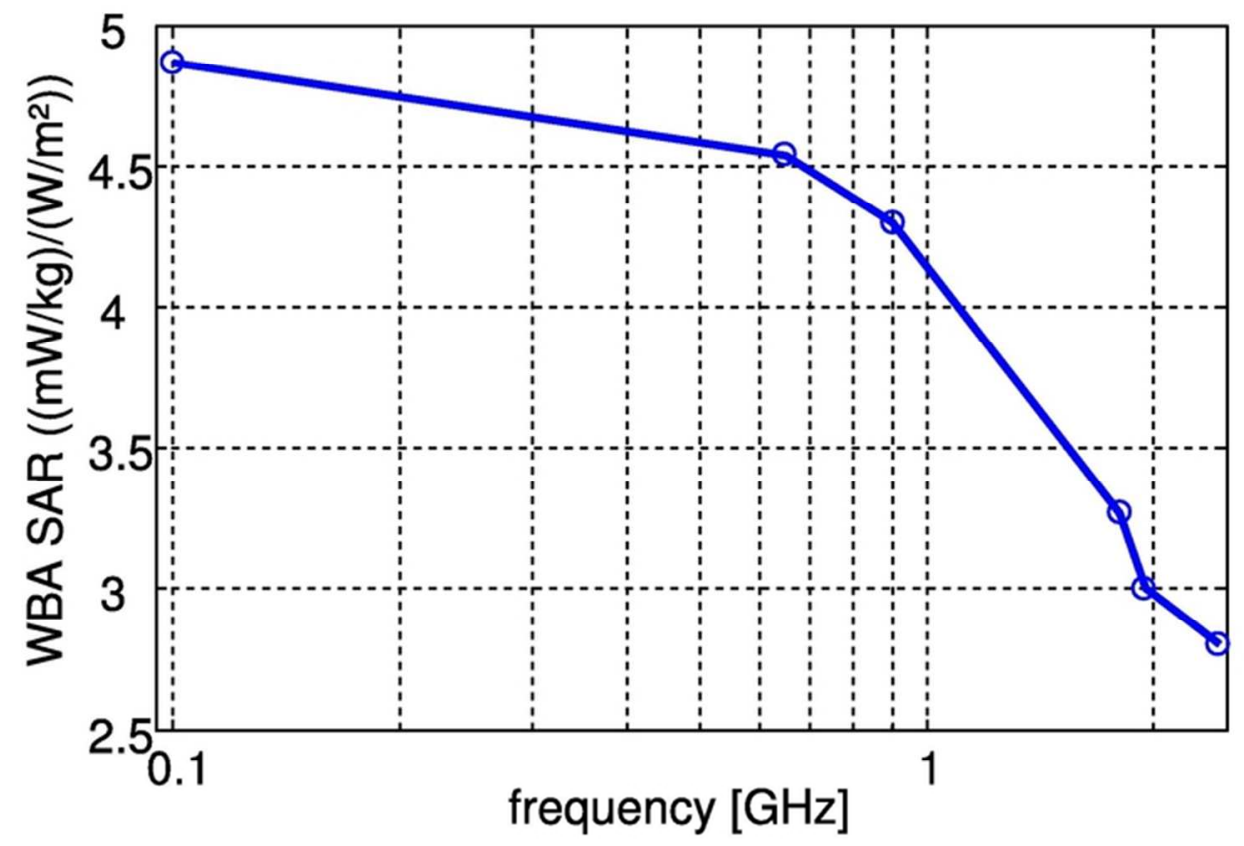

Figure 2: Whole-body averaged (WBA) specific absorption rate (SAR) for plane waves coming from the six major incident directions with two polarizations each at $100 \mathrm{MHz}, 650 \mathrm{MHz}, 900 \mathrm{MHz}, 1800 \mathrm{MHz}, 1950 \mathrm{MHz}$ and $2450 \mathrm{MHz}$. The results are averaged over all incident directions and normalized to a power flux density of $1 \mathrm{~W} / \mathrm{m}^{2}$.

$65 \times 49 \mathrm{~mm}(300 \times 300 \mathrm{DPI})$ 


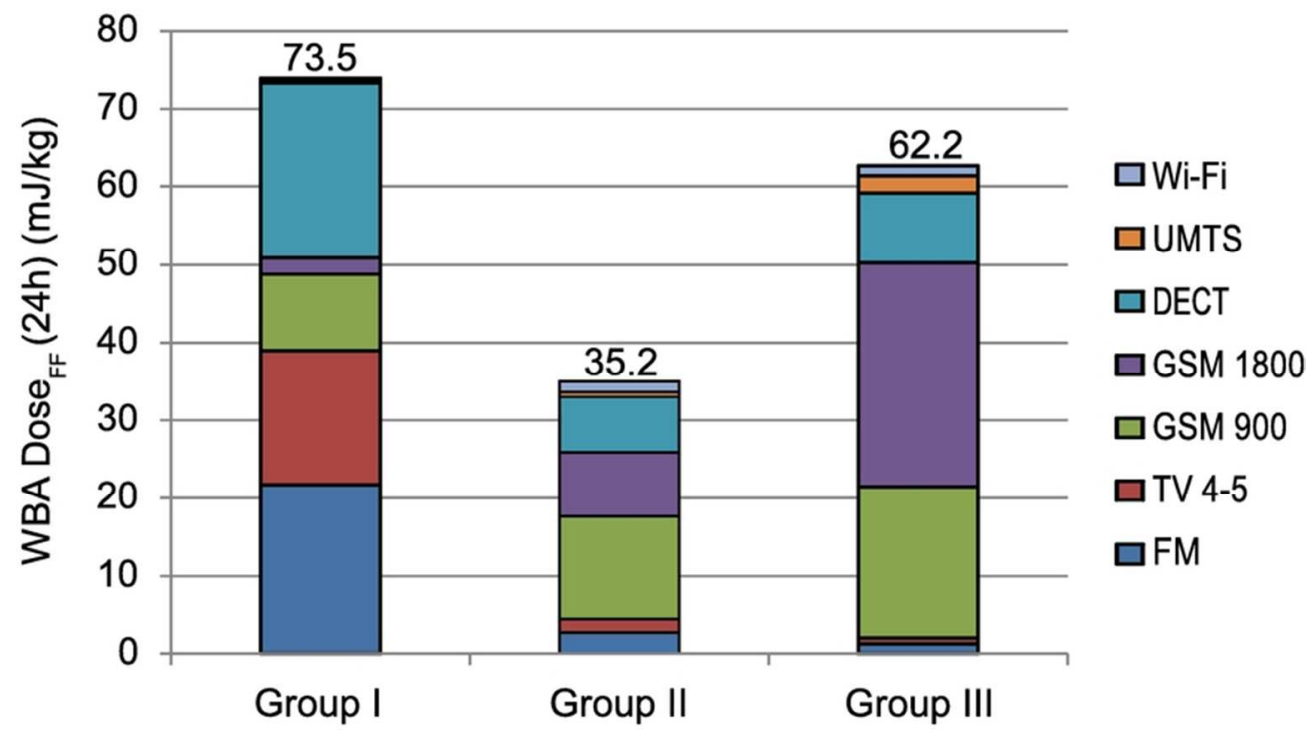

Figure 3: Contribution of different far field (FF) services to the "WBA DoseFF(24h)" for different study groups. Group I: persons with residency close to a broadcast transmitter, Group II: self-selected volunteers, Group III: persons with residency close to a mobile phone base station. $74 \times 41 \mathrm{~mm}(300 \times 300$ DPI $)$ 


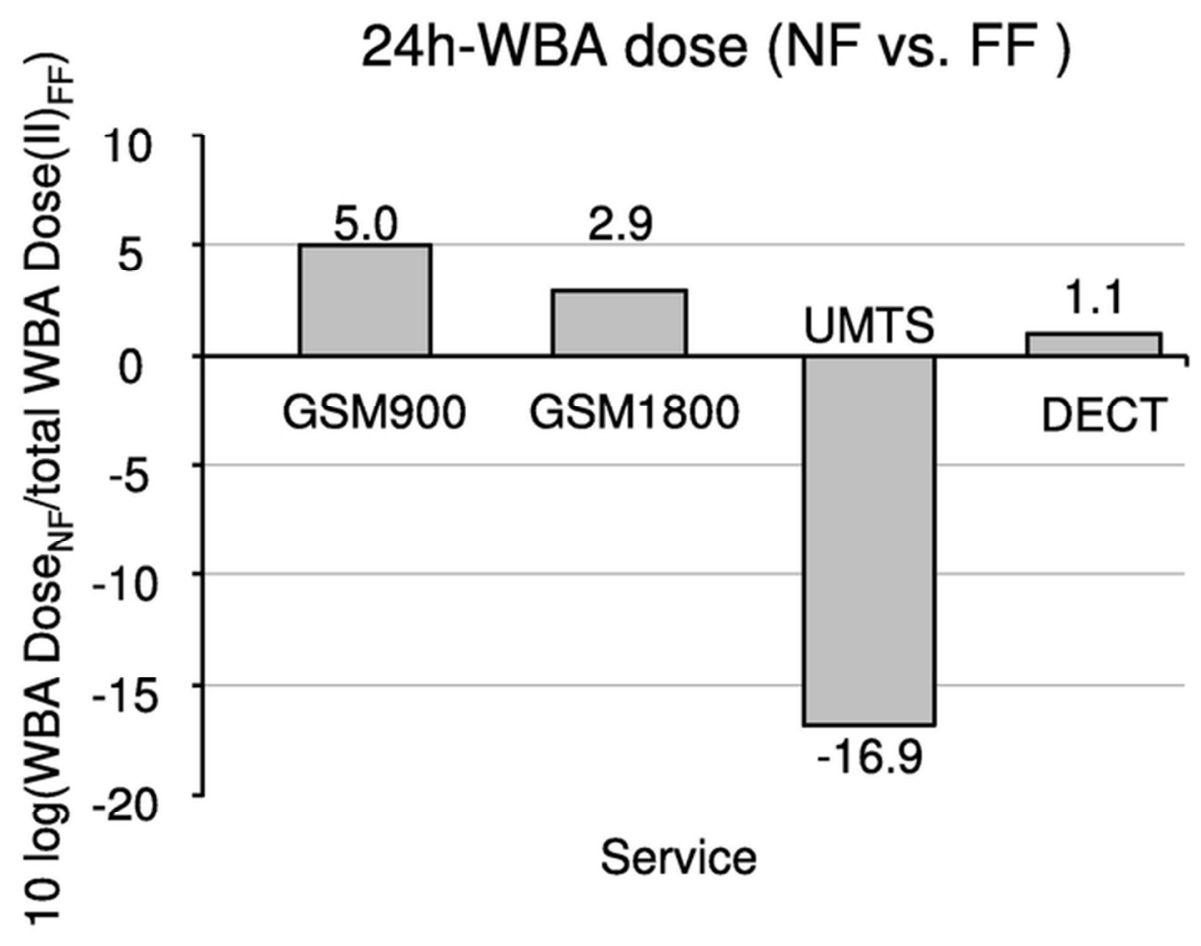

Figure 4: "WBA Dose ratio(24h)" caused by near field (NF) and far field (FF) sources for an average mobile phone user of Group II. $63 \times 46 \mathrm{~mm}(300 \times 300 \mathrm{DPI})$ 


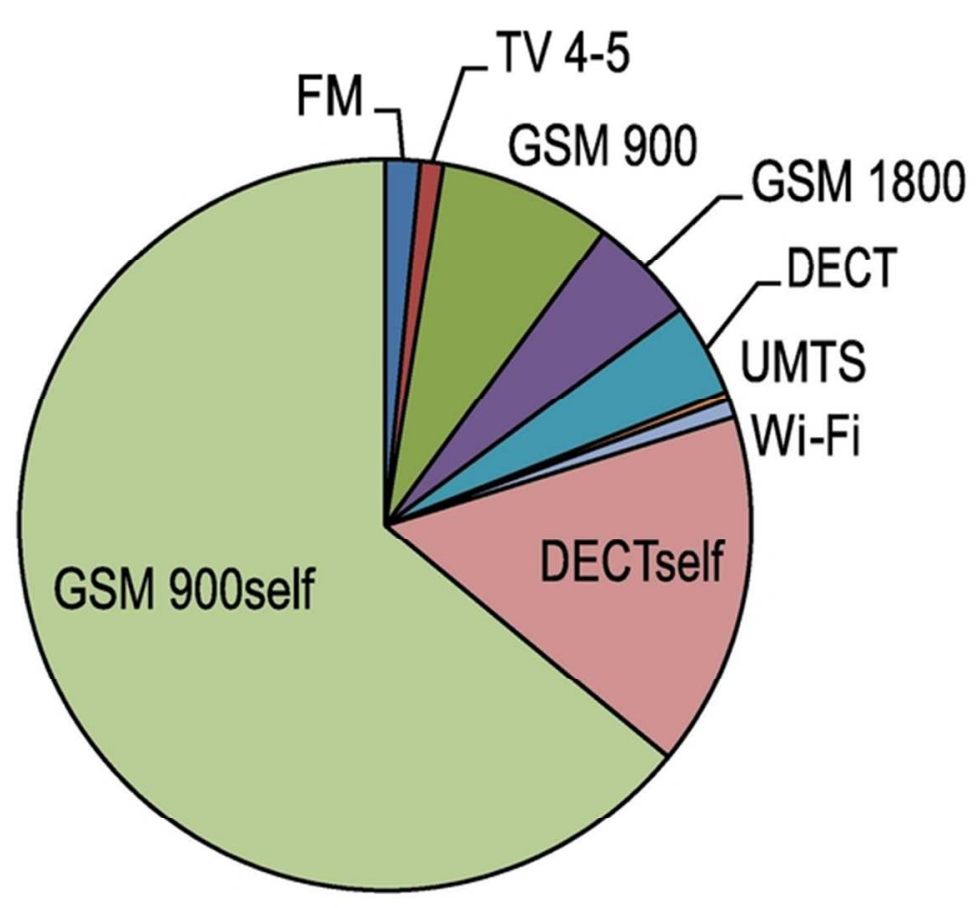

Figure 5: Contribution of the different services to the total "WBA Doseall(24h)" for a person from the study Group II. We assume that the person uses the GSM 900 service for $25.6 \mathrm{~min} /$ week and the DECT service for $61.6 \mathrm{~min} /$ week. The contribution of the self-induced exposure dose is indicated in the legends with the abbreviation 'self'. $65 \times 49 \mathrm{~mm}(300 \times 300 \mathrm{DPI})$ 


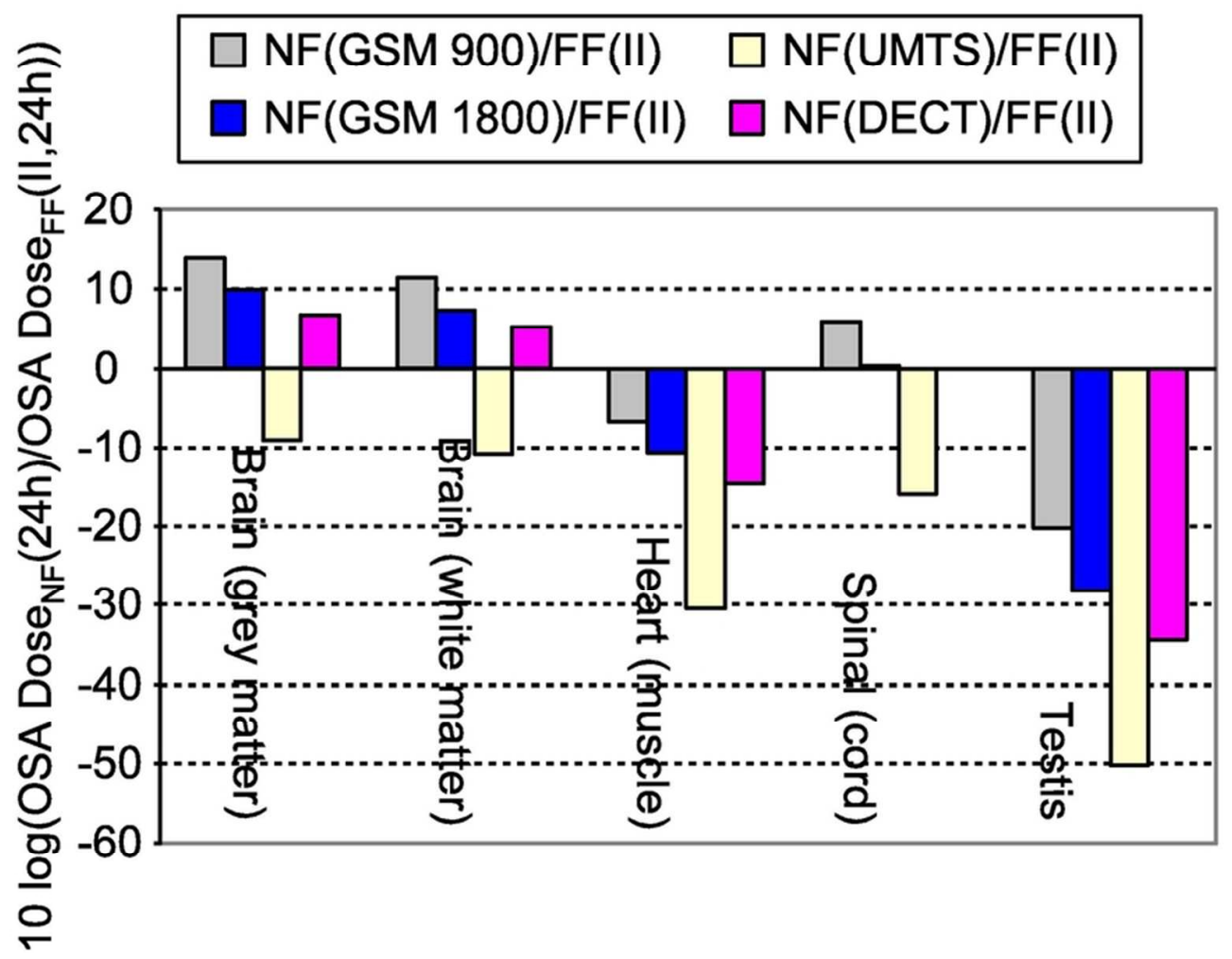

Figure 6: Comparison of OSA dose for the study group II and the usage of different mobile and cordless phone standards. The average call time is $25.6 \mathrm{~min} /$ week for GSM 900, GSM 1800 and UMTS. For DECT an average call time of $61.6 \mathrm{~min} /$ week is assumed. $74 \times 63 \mathrm{~mm}(300 \times 300 \mathrm{DPI})$ 
Table 1

\begin{tabular}{|l|r|r|r|}
\hline \multicolumn{4}{|c|}{ Table 1 } \\
\hline \multirow{2}{*}{ Service } & \multicolumn{3}{|c|}{$\mathrm{S}\left(\mu \mathrm{W} / \mathrm{m}^{2}\right)$} \\
\cline { 2 - 4 } & Group I & Group II & Group III \\
\hline FM & 51.6 & 6.32 & 2.89 \\
\hline TV 4-5 & 44.1 & 4.48 & 2 \\
\hline GSM 900 & 26.32 & 35.53 & 52.28 \\
\hline GSM 1800 & 7.43 & 29.27 & 102.17 \\
\hline DECT & 85.5 & 27.2 & 33.9 \\
\hline UMTS & 1.11 & 2.35 & 8.28 \\
\hline Wi-Fi & 1.38 & 5.85 & 5.25 \\
\hline
\end{tabular}

\section{Page 1}

John Wiley \& Sons 
1

2

3

4

5

6

7

8

9

10

11

12

13

14

15

16

17

18

19

20

21

22

23

24

25

26

27

28

29

30

31

32

33

34

35

36

37

38

39

40

41

42

43

44

45

46

47

48

49

50

51

52

53

54

55

56

57

58

59

60

Table 2

\begin{tabular}{|l|r|r|}
\hline \multicolumn{3}{|c|}{ Table 2 } \\
\hline \multicolumn{1}{|c|}{ Service } & average transmission (TX) power $(\mathrm{mW})$ & average call time (min/week) \\
\hline GSM 900 & 133 & 25.6 \\
\hline GSM 1800 & 62.2 & 25.6 \\
\hline UMTS & 0.65 & 25.6 \\
\hline DECT & 10.4 & 61.6 \\
\hline
\end{tabular}

\section{Page 1}

John Wiley \& Sons 
Table 3

\begin{tabular}{|r|r|}
\hline \multicolumn{2}{|c|}{ Table 3 } \\
\hline Frequency $(\mathrm{MHz})$ & WBA SAR $\left((\mathrm{W} / \mathrm{kg}) /\left(\mathrm{W} / \mathrm{m}^{2}\right)\right)$ \\
\hline 900 & 3.85 \\
\hline 1800 & 4.99 \\
\hline 1950 & 4.95 \\
\hline
\end{tabular}


Table 4

\begin{tabular}{|l|r|r|r|r|r|r|}
\hline \multicolumn{7}{|c|}{ Table 4 } \\
\hline \multirow{2}{*}{ Organs/Tissues } & \multicolumn{7}{|c|}{ OSA SAR $\mathrm{FF}\left((\mu \mathrm{W} / \mathrm{kg}) /\left(\mathrm{W} / \mathrm{m}^{2}\right)\right)$} \\
\cline { 2 - 7 } & $100 \mathrm{MHz}$ & $650 \mathrm{MHz}$ & $900 \mathrm{MHz}$ & $1800 \mathrm{MHz}$ & $1950 \mathrm{MHz}$ & $2450 \mathrm{MHz}$ \\
\hline Adrenal gland & 807.3 & 1090.1 & 108.2 & 14.7 & 6.1 & 0.6 \\
\hline Brain grey matter & 1433.2 & 7608.1 & 6874.5 & 3246.5 & 2911.1 & 2288.9 \\
\hline Brain white matter & 915.2 & 5301.1 & 4120.6 & 1943.7 & 1600.8 & 1095.9 \\
\hline Cerebellum & 1381.9 & 5229.0 & 8913.6 & 1804.3 & 1690.6 & 1262.3 \\
\hline Cerebrospinal fluid & 3524.3 & 16120.1 & 12381.7 & 5264.6 & 4712.6 & 3977.6 \\
\hline Eye lens & 1404.4 & 7840.1 & 5071.3 & 3091.2 & 4716.3 & 6793.9 \\
\hline Heart muscle & 2026.6 & 1072.4 & 972.9 & 224.7 & 218.6 & 185.8 \\
\hline Hippocampus & 657.4 & 3706.3 & 3796.9 & 1069.8 & 868.4 & 456.3 \\
\hline Hypophysis & 342.3 & 1849.7 & 813.9 & 103.9 & 53.5 & 16.9 \\
\hline Hypothalamus & 507.9 & 7970.2 & 6717.8 & 586.3 & 426.4 & 40.1 \\
\hline Kidney medulla & 2275.2 & 1756.8 & 838.3 & 209.4 & 113.8 & 44.4 \\
\hline Marrow red & 2268.7 & 2551.0 & 2738.3 & 1744.3 & 1638.6 & 1626.6 \\
\hline Medulla oblongata & 214.3 & 1750.7 & 2870.4 & 274.8 & 172.7 & 30.4 \\
\hline Midbrain & 341.8 & 5062.0 & 3101.1 & 554.8 & 360.6 & 93.0 \\
\hline Nerve & 1594.0 & 1073.1 & 1121.5 & 381.1 & 291.6 & 141.7 \\
\hline Pineal body & 829.9 & 7962.0 & 5180.7 & 729.1 & 638.0 & 121.5 \\
\hline Pons & 245.0 & 1883.4 & 2168.8 & 98.7 & 62.5 & 14.8 \\
\hline Skin & 6541.2 & 9637.5 & 11424.8 & 12259.6 & 11799.4 & 12443.3 \\
\hline Spinal cord & 946.1 & 1801.2 & 1074.6 & 216.1 & 127.0 & 44.1 \\
\hline Testis & 17103.8 & 13370.3 & 6024.1 & 7641.2 & 7749.7 & 8014.8 \\
\hline Thalamus & 463.9 & 7831.5 & 4227.7 & 1323.0 & 773.7 & 141.5 \\
\hline Thymus & 2672.4 & 2984.3 & 1731.3 & 309.7 & 737.8 & 1199.6 \\
\hline Thyroid gland & 3802.6 & 13433.4 & 2515.0 & 7014.4 & 9047.9 & 4520.0 \\
\hline Vertebrae & 254.8 & 201.1 & 225.4 & 95.7 & 76.8 & 51.2 \\
\hline
\end{tabular}

Page 1 
Table 5

\begin{tabular}{|l|r|r|r|}
\hline \multicolumn{4}{|c|}{ Table 5} \\
\hline \multirow{2}{*}{ Organs/Tissues } & OSA SAR & & \\
\cline { 2 - 4 } & $900 \mathrm{MHz}$ & $1800 \mathrm{MH} / \mathrm{kg}) /\left(\mathrm{W} / \mathrm{m}^{2}\right)$ & $1950 \mathrm{MHz}$ \\
\hline Adrenal gland & 2.3 & 0.3 & 1.6 \\
\hline Brain grey matter & 34319.9 & 29456.9 & 35865.0 \\
\hline Brain white matter & 11622.7 & 9586.9 & 14647.3 \\
\hline Cerebellum & 20584.8 & 19225.3 & 22239.1 \\
\hline Cerebrospinal fluid & 40566.4 & 25729.2 & 37429.8 \\
\hline Eye lens & 14424.5 & 11984.3 & 22280.3 \\
\hline Heart muscle & 41.6 & 36.2 & 37.2 \\
\hline Hippocampus & 37256.9 & 34057.1 & 79183.0 \\
\hline Hypophysis & 27141.1 & 1215.8 & 2919.7 \\
\hline Hypothalamus & 38010.9 & 9657.6 & 34089.0 \\
\hline Kidney medulla & 8.2 & 3.0 & 6.9 \\
\hline Marrow red & 1583.5 & 2447.8 & 1703.9 \\
\hline Medulla oblongata & 8889.2 & 1647.2 & 4793.4 \\
\hline Midbrain & 18961.9 & 8002.0 & 26059.7 \\
\hline Nerve & 788.7 & 314.7 & 638.4 \\
\hline Pineal body & 8904.1 & 5782.9 & 26887.3 \\
\hline Pons & 8823.9 & 1224.4 & 4771.7 \\
\hline Skin & 7210.5 & 13444.0 & 11297.6 \\
\hline Spinal cord & 724.9 & 411.6 & 969.8 \\
\hline Testis & 25.0 & 8.6 & 5.3 \\
\hline Thalamus & 13339.4 & 6274.6 & 25476.5 \\
\hline Thymus & 48.3 & 76.1 & 58.6 \\
\hline Thyroid gland & 1606.8 & 2891.5 & 2567.6 \\
\hline Vertebrae & 270.5 & 181.1 & 280.9 \\
\hline
\end{tabular}

Page 1 
Table 6

\begin{tabular}{|l|r|}
\hline \multicolumn{2}{|c|}{ Table 6 } \\
\hline Service & WBA Dose $_{\mathrm{NF}}(24 \mathrm{~h})(\mathrm{mJ} / \mathrm{kg})$ \\
\hline GSM 900 & 111 \\
\hline GSM 1800 & 68.5 \\
\hline UMTS & 0.71 \\
\hline DECT & 27.2 \\
\hline
\end{tabular}

10

11

12

13

14

15

16

17

18

19

20

21

22

23

24

25

26

27

28

29

30

31

32

33

34

35

36

37

38

39

40

41

42

43

44

45

46

47

48

49

50

51

52

53

54

55

56

57

58

59

60

Page 1

John Wiley \& Sons 
Table 7

\begin{tabular}{|c|c|c|c|c|c|c|c|}
\hline \multicolumn{8}{|c|}{ Table 7} \\
\hline \multirow{2}{*}{ Organs/Tissues } & \multicolumn{3}{|c|}{ DoseFF(24h) (mJ/kg) } & \multicolumn{4}{|c|}{ DoseNF(24h) (mJ/kg) } \\
\hline & Group I & Group II & Group III & GSM 900 & GSM 1800 & UMTS & DECT \\
\hline Adrenal gland & 8.0542 & 1.2478 & 1.0307 & 0.0657 & 0.0042 & 0.0002 & 0.009 \\
\hline Brain grey matter & 75.1546 & 41.6289 & 73.026 & 1001.591 & 403.9805 & 5.1154 & 96.942 \\
\hline Brain white matter & 47.0083 & 24.7568 & 43.2435 & 339.1977 & 131.4774 & 2.0891 & .4311 \\
\hline Cerebellum & 60.3167 & 39.6575 & 64.1688 & 600.746 & 263.661 & 3.1719 & 122.119 \\
\hline Cerebrospinal fluid & 144.414 & 73.5274 & 125.037 & 1183.89 & 352.8581 & 5.3386 & 205.535 \\
\hline Eye lens & 85.7567 & 42.6606 & 72.1646 & 420.964 & 164.3566 & 3.1778 & 122.346 \\
\hline Heart muscle & 17.1356 & 5.7278 & 7.9504 & 1.2136 & 0.4966 & 0.0053 & 0.2044 \\
\hline Hippc & 32.9275 & 18.602 & 30.7686 & 1087.305 & 467.0693 & 11.294 & 434.81 \\
\hline Hypc & 10.8944 & 3.8092 & 5.2001 & 79 & 16.6739 & 0.4164 & 326 \\
\hline Hypc & 51.4839 & 26.5766 & 38.5918 & 110 & 32.4475 & 4.8621 & 189 \\
\hline Kidne & 19.7342 & 5.3374 & 6.9412 & 391 & 0.0416 & 0.001 & 379 \\
\hline Marro & 39.6372 & 20.0476 & 35.4825 & 46.212 & 33.5704 & 0.243 & 9.3563 \\
\hline Medulla oblor & 15.6263 & 10.7572 & 16.389 & 259.4218 & 22.5896 & 0.6837 & 26.3216 \\
\hline Midbrain & 30.9304 & 14.0365 & 21.2186 & 553 & 109.7424 & 3.7169 & 143.099 \\
\hline Nerve & 16.1886 & 6.5076 & 10.1403 & 23.0176 & 4.3153 & 0.0911 & 3.5054 \\
\hline Pineal & 51.0771 & 22.9728 & 33.796 & 259.856 & 79.309 & 3.8349 & 147.644 \\
\hline Pons & 13.7333 & 7.9369 & 11.287 & 257.5164 & 16.7915 & 0.6806 & 26.2026 \\
\hline Skin & 189.519 & 109.786 & 211.767 & 210 & 184.3752 & 1.6114 & 373 \\
\hline Spinal c & 14.6193 & 5.4052 & 7.791 & 57 & 5.645 & 0.1383 & 251 \\
\hline Testis & 204.748 & 76.1599 & 133.12 & 303 & 0.1176 & 0.0008 & 0.0291 \\
\hline Thalamus & 48.1802 & 21.6558 & 35.1249 & 389.298 & 86.0515 & 3.6337 & 139.897 \\
\hline Thymus & 33.0857 & 11.2013 & 14.9688 & 1.4086 & 1.0437 & 0.0084 & 0.3215 \\
\hline Thyroid $\mathrm{g}$ & 146.608 & 58.1179 & 111.57 & 46.8943 & 39.6548 & 0.3662 & 14.0992 \\
\hline Vertebrae & 3.057 & 1.3726 & 2.2641 & 7.8947 & 2.4835 & 0.0401 & 1.5427 \\
\hline
\end{tabular}

\section{Page 1}

